\title{
Allergic Bronchopulmonary Aspergillosis in Children with Cystic Fibrosis: An Update on the Newest Diagnostic Tools and Therapeutic Approaches
}

\author{
Claudia Lattanzi, Giulia Messina, Valentina Fainardi, Maria Candida Tripodi, Giovanna Pisi and \\ Susanna Esposito * (D) \\ Pediatric Clinic, Pietro Barilla Children's Hospital, Department of Medicine and Surgery, University of Parma, \\ 43126 Parma, Italy; claudial1992@gmail.com (C.L.); messina.giulia@gmail.com (G.M.); \\ valentina.fainardi@gmail.com (V.F.); mtripodi@ao.pr.it (M.C.T.); gpisi@ao.pr.it (G.P.) \\ * Correspondence: susanna.esposito@unimi.it; Tel.: +39-0521-903524
}

Received: 3 July 2020; Accepted: 27 August 2020; Published: 31 August 2020

\begin{abstract}
Cystic fibrosis (CF), the most common autosomal-recessive genetic disease in the Caucasian population, is characterized by frequent respiratory infections and progressive lung disease. Fungal species are commonly found in patients with $\mathrm{CF}$, and among them, Aspergillus fumigatus is the most frequently isolated. While bacteria, particularly Pseudomonas aeruginosa, have a well-established negative effect on $\mathrm{CF}$ lung disease, the impact of fungal infections remains unclear. In patients with CF, inhalation of Aspergillus conidia can cause allergic bronchopulmonary aspergillosis (ABPA), a Th2-mediated lung disease that can contribute to disease progression. Clinical features, diagnostic criteria and treatment of ABPA are still a matter of debate. Given the consequences of a late ABPA diagnosis or the risk of ABPA overdiagnosis, it is imperative that the diagnostic criteria guidelines are reviewed and standardized. Along with traditional criteria, radiological features are emerging as tools for further classification as well as novel immunological tests. Corticosteroids, itraconazole and voriconazole continue to be the bedrock of ABPA therapy, but other molecules, such as posaconazole, vitamin D, recombinant INF- $\gamma$ and Cystic Fibrosis Transmembrane Conductance Regulator (CFTR) modulators, have been showing positive results. However, few studies have been conducted recruiting CF patients, and more research is needed to improve the prevention and the classification of clinical manifestations as well as to personalize treatment. Early recognition and early treatment of fungal infections may be fundamental to prevent progression of $\mathrm{CF}$ disease. The aim of this narrative review is to give an update on ABPA in children with CF.
\end{abstract}

Keywords: allergic bronchopulmonary aspergillosis; Aspergillus fumigatus; cystic fibrosis; lung disease

\section{Background}

Aspergillus species are ubiquitous saprophytic fungi found in water, soils, organic decay and in indoor environments. The commonest species associated to respiratory disease in humans is Aspergillus fumigatus. Aspergillus spores are inhaled daily, usually with no consequences, but, in susceptible people with pulmonary diseases such as cystic fibrosis (CF), the inhalation of Aspergillus conidia can colonize the lung and cause allergic bronchopulmonary aspergillosis (ABPA) [1]. ABPA is a Th2-mediated lung disease caused by hypersensitivity to Aspergillus hyphae that carries significant morbidity for patients with $\mathrm{CF}$ and may progress to bronchiectasis and pulmonary fibrosis. While bacterial infections, particularly those with $P$. aeruginosa, have a well-established negative effect on CF lung disease, the impact of fungal infections remains unclear [2], but an early diagnosis of ABPA seems clinically relevant in order to avoid deterioration of lung function [3]. 
The aim of this narrative review is to give an update on ABPA in children with $\mathrm{CF}$, particularly regarding the newest diagnostic tools and therapeutic approaches.

\section{Epidemiology of Aspergillus fumigatus in Patients with CF}

Fungi are commonly found in patients with CF, and Aspergillus fumigatus is the most frequently isolated, with sputum samples found positive in $16 \%$ of children and adolescents [3] and up to $58 \%$ when also including older patients [4]. The use of specific fungal diagnostic protocols consisting of selective media for fungi and molecular methods has significantly increased Aspergillus detection in recent years [5]. In a recent study, Reece et al. [6] demonstrated that an extended incubation period and the use of quantitative polymerase chain reaction (qPCR) increased the detection of A. fumigatus in sputum samples from 16 to $52 \%$ of patients compared to the routine culture method.

Colonization of the airways can be suspected when Aspergillus is cultured in two or more samples over a year in patients without new respiratory symptoms and no specific fungal IgG in serum $[5,7]$. In younger children, data are unclear and colonization prevalence may be underestimated because this age group rarely produce a sputum and microbiological results rely on cough swabs. A retrospective study on 45 patients with CF analysed bronchoalveolar lavage (BAL) in very young children unable to expectorate and sputum in older children reporting an overall colonization prevalence of $22 \%$ with a higher risk over 8 years of age [8]. In an Australian cohort of preschool CF children, Aspergillus was the most frequently isolated pathogen in BAL on annual surveillance bronchoscopies, with a prevalence of $11 \%$ [9]. However, a positive culture for Aspergillus from sputum does not imply the development of ABPA because of the heterogeneity of the interaction between the fungus and the host. In fact, allergy to Aspergillus antigens detected by skin prick test is described in almost $50 \%$ of CF patients, whilst the prevalence of ABPA is estimated to be between $10 \%$ and $25 \%$ depending on the studies [10-14]. However, ABPA may be often underdiagnosed due to the lack of standardized diagnostic criteria.

\section{Risk Factors for Aspergillus Colonization and Infection in Patients with CF}

In $\mathrm{CF}$, the main predisposing factor for colonization and eventually infection is impaired muco-ciliary clearance due to the dysfunction of Cystic Fibrosis Transmembrane Conductance Regulator (CFTR) that leads to a decrease in airway-surface liquid $\mathrm{pH}$ resulting in reduced antimicrobial activity and increased mucus viscosity [5].

Among colonized patients, many become sensitized to A. fumigatus with specific IgE or IgG, some produce a robust allergic response with high total IgE and high eosinophils [15] and only a small part develop ABPA [16]. The reasons why the clinical picture varies among patients are different and include clinical status, microbial interactions, medications, atopy and genetic immune host susceptibility.

A recent large multicentre study on 1541 subjects (mean age 15 years) with CF who developed chronic isolation of Aspergillus (two or more positive cultures during the 12-month period after the first positive result) demonstrated that pancreatic insufficiency was the greatest risk factor for Aspergillus infection, followed by use of macrolides and inhaled antibiotics and steroids [17]. In a study conducted in 26 children, low body mass index (BMI) led to a 10-fold increased risk of ABPA [18]. However, these findings are not conclusive since Aspergillus could be more frequent in patients with more severe disease and therefore requiring more long-term antibiotic therapies. It has been argued that aggressive antibiotic therapies such as long-term azithromycin and chronic inhaled antibiotics in early age may have decreased the prevalence of S. aureus and Pseudomonas aeruginosa but increased Aspergillus airway colonization, as shown by Breuer et al. [9]. The mechanism behind the association between long-term therapy with macrolides and risk of Aspergillus colonization would be the inhibitory effect of azithromycin on the recruitment and activation of neutrophils, the first-line defences against Aspergillus [18]. With regard to genetic predisposing factors, HLA DR2 and DR5, and possibly DR4 and DR7, have been suggested to increase the risk for ABPA, whereas HLA DQ2 seems to be protective $[19,20]$. Furthermore, Brouad et al. reported a specific genotype in the IL-10 promotor region 
as a predisposing factor of Aspergillus colonization and ABPA development [21]. Many associations between ABPA and SNPs for IL-4 receptor, IL-13 and Toll-like receptor (TLR) 3 have been found in people without $\mathrm{CF}$ suggesting that genetic predisposition can be the cause of the aberrant response to A. fumigatus and susceptibility to ABPA seen in certain individuals [22].

Moreover, alterations in the airway microbiome may be a predisposing factor for fungal colonization and development of ABPA in patients susceptible to aspergillosis [23] and these alterations might be enhanced by the frequent use of antibiotics in patients with CF [24]. In summary, the interplay between Aspergillus virulence and host-susceptibility determines the onset and the course of the disease.

\section{Pathogenesis of Aspergillus fumigatus Infection in Patients with CF}

It is well established that ABPA is caused by hypersensitivity to Aspergillus antigens but why only some patients develop the allergy and the disease remains unclear

In susceptible hosts, inhaled spores of Aspergillus germinate to hyphae and persist into the lungs, leading to the damage of muco-ciliary clearance and epithelium barrier and eventually activating a strong type 2 immune response $[25,26]$. Type 2 immune response is characterized by the production of IL-4, IL-5 and IL-13 from innate lymphoid cells, Th2 cells and eosinophils, mast cell degranulation, eosinophil activation with an increase in total IgE, Aspergillus-specific IgE and the production of Aspergillus-specific IgG antibodies [10,18]. The consequent pulmonary eosinophilic inflammation results in recurrent pulmonary infiltrates and eventually in bronchiectasis and pulmonary fibrosis.

In patients with altered lung structure, such as CF patients where the innate defense of mucociliary clearance is impaired, Aspergillus spores penetrate and adhere to collagen and fibronectin fibres in the basal lamina, facilitating its persistence into the airways [27]. Moreover, the fungal metabolite gliotoxin has been shown to downregulate vitamin $\mathrm{D}$ receptor expression in macrophages and airway epithelial cells of CF patients and increase the levels of IL-5 and IL-13 [28]. In CFTR-deficient mice, even in the absence of ABPA, Aspergillus elicits an aberrant Th2 immune response with increased levels of IL-4, IL-13 and IgE [28].

Allergenic proteinases secreted by Aspergillus are considered the main pathogenic factor that facilitates the fungal persistence in respiratory airways. Aspergillus proteinases are recognized by the innate immune receptors TLR 2, TLR4 and TLR6 resulting in the initiation of allergic airway inflammation with activation of both innate and adaptive immunity and release of pro-inflammatory cytokines [29-31].

Although eosinophils have been traditionally implicated in fighting fungal infections, the latest evidence attributes to Th2 cytokines an important role in this hypersensitivity reaction. Flow cytometer studies on peripheral blood of CF patients with ABPA showed a skewing towards Th2 cells with a reduction in IFNg production and murine models confirmed that CFTR mutation is associated with an increased sensitivity to IL-4 [28,32].

Dietschmann et al. concluded that T-cell-derived IL-4/IL-13 is essential for A. fumigatus-induced lung eosinophilia and inflammation, while eosinophils seem to have immunomodulatory and not only inflammatory function [33]. Taken together, these results suggest that the increased susceptibility of CF patients to ABPA might be due to an exaggerate Th2 response and a deficient Th1 response.

Nevertheless, a clear understanding of the pathophysiological mechanisms determining allergic and chronic forms of pulmonary aspergillosis such as ABPA has been limited by the lack of reliable murin models of Aspergillus colonization, the prerequisite of fungal infection [34].

\section{Clinical Features of ABPA in Patients with CF}

In $\mathrm{CF}$, the interaction between the host and A. fumigatus can range from asymptomatic conditions to rapidly invasive disseminated diseases, as follows: (1) colonization, (2) serological sensitization (3) Aspergillus bronchitis, (4) chronic pulmonary aspergillosis or (5) allergic aspergillosis. These diseases can present as ABPA, Aspergillus-induced asthma (AIA) or allergic Aspergillus sinusitis (AAS). One form of clinical disease may evolve into another. Colonization is defined when two or more respiratory 
samples are positive for Aspergillus by culture or PCR in patients without new respiratory symptoms and no fungal specific IgG in serum [7]. Fungal bronchial colonization leads to airway inflammation and eventually to the development of allergic forms of aspergillosis [35]. The presence of serum IgE specific to Aspergillus without symptoms describes the fungal serological sensitization; this can be associated with a skin prick test positive for Aspergillus. Aspergillus bronchitis is a chronic infection of the lower respiratory airways that may affect about $9 \%$ of CF individuals [36]. Symptomatic patients with a positive culture for Aspergillus (or PCR), Aspergillus-specific IgG or precipitins but that do not fulfil the diagnostic criteria for ABPA or invasive aspergillosis may have Aspergillus bronchitis. Chronic pulmonary aspergillosis is characterized by progressive cavitation, fibrosis and pleural thickening; a fungal ball called aspergilloma may appear in the cavity [25]. There is a strong association between nontuberculous mycobacterial infection and chronic pulmonary aspergillosis [35]. ABPA can present with great variability; patients can initially be asymptomatic or slightly symptomatic with fatigue, persistent mild cough, increased sputum, haemoptysis, fever, malaise and exercise-induced dyspnoea or, conversely, the onset might be acute and seldom fulminant [26,35]. The progression of ABPA can be summarized in five stages, as reported in Table 1 [37].

The mechanisms determining the predisposition towards certain clinical manifestations are not yet fully understood, but the pathogenicity of the fungus and the host immunity are supposed to be the main implicated factors.

Table 1. Stages of allergic bronchopulmonary aspergillosis (ABPA), adapted from Patel et al. [37].

\begin{tabular}{c} 
Stage \\
Stage I, acute \\
$\begin{array}{c}\text { The patient is diagnosed with all typical features (Aspergillus-specific IgE, radiological abnormalities, peripheral } \\
\text { blood eosinophilia, Aspergillus-specific serum precipitins) }\end{array}$ \\
\hline
\end{tabular}

Stage II, remission

Asymptomatic patient, no new radiological infiltrates, no rise in total $\operatorname{IgE}$ for at least 6 months

Stage III, exacerbation

New pulmonary infiltrates on chest X-ray with peripheral blood eosinophilia and double the remission IgE level

Stage IV, corticosteroid-dependent asthma

Inability to taper off from corticosteroid treatment

Stage $\mathrm{V}$, fibrotic lung disease

Irreversible fibrosis and chronic cavitation at X-ray and CT scan

\section{ABPA and Lung Function}

The impact of ABPA on the decline in lung function remains unclear. In their longitudinal data analysis of 3350 patients, Kaditis et al. found that the difference in forced expiratory volume in one second (FEV1) between children with and without ABPA was modest. During a 3-year follow-up, FEV1 was significantly lower in children with ABPA during the first year; no significant difference was observed in the subsequent years [38]. De Baets et al. performed a retrospective case-control study in 73 P. aeruginosa-negative patients and found that patients with ABPA had significantly lower FEV1 values. They suggested that this decline in lung function preceded ABPA diagnosis by approximately 2 years [39]. When other factors were analysed, a low BMI Z-score was found to have the greatest impact on the progression of lung disease followed by high-risk genotype, female sex, CF-related diabetes mellitus, chronic P. aeruginosa infection and, last, ABPA [38].

A cross-sectional analysis carried out by Harun et al. in 5- to 14-year-old children with BAL positive for Aspergillus fumigatus reported increased chest CT scores for air trapping at age 5 years [40]. Similarly, an interesting study by Breuer et al. in 330 children with CF demonstrated that Aspergillus infection was associated to progression of structural lung disease (especially air trapping) at annual chest CT scan and to increased risk of hospitalization [41]. Both studies reported no association between the presence of Aspergillus in BAL and lung function. 
At present, there is no consensus for the treatment of asymptomatic Aspergillus colonization in CF, but numerous studies have concluded that patients chronically colonized with $A$. fumigatus have a more rapid decline in FEV1 than non-colonized patients [3,8,42]. Furthermore, co-colonization between A. fumigatus and P. aeruginosa is associated with poorer clinical outcomes [43].

\section{Diagnosis of ABPA in Patients with CF}

Diagnosis of ABPA in CF patients remains challenging because ABPA can overlap other syndromes, such as chronic pulmonary aspergillosis or, when complicated by bronchiectasis, Aspergillus bronchitis [13]. In the non-CF population, the presence of bronchiectasis and chest infiltrates can orientate the clinician for a diagnosis of ABPA, but, in CF, these features are typical, making the distinction between type 2 high fungal allergen-exacerbated asthma very difficult. Moreover, there is no consensus regarding the cut-off values for the diagnostic serological tests in CF because most studies have been performed in asthma patients [35]. Over the last 50 years, several diagnostic criteria have been proposed, but a consensus has not been reached [37]. To date, four different working groups have proposed diagnostic criteria in order to help clinicians in identifying this entity.

The Rosenberg and Patterson criteria included eight major (asthma, transient pulmonary infiltrates, immediate cutaneous reactivity to A. fumigatus, elevated total serum IgE, precipitating antibodies against $A$. fumigatus, peripheral blood eosinophilia, elevated serum IgE and IgG to A. fumigatus, central/proximal bronchiectasis with normal tapering of distal bronchi) and three minor criteria (expectoration of golden-brownish sputum plugs, positive sputum culture for Aspergillus species, late skin reactivity to $A$. fumigatus), as shown in Table 2 . The presence of six out of eight major criteria makes diagnosis almost certain.

In 2003, the Cystic Fibrosis Foundation held a consensus conference to revise pre-existing criteria. They identified five criteria as follows: acute or subacute clinical deterioration in pulmonary function, serum total IgE concentration $>1000 \mathrm{IU} / \mathrm{mL}$ unless the patient is receiving systemic corticosteroids, positive serum-specific IgE ( $>0.35 \mathrm{kUA} / \mathrm{L})$ or immediate skin test, precipitating antibodies to A. fumigatus or serum IgG antibodies to A. fumigatus by an in vitro test, and new or recent infiltrates (or mucus plugging) on radiological imaging that do not respond to antibiotics and standard physiotherapy. The criteria are shown in Table 3 [14].

Table 2. Diagnostic criteria for allergic bronchopulmonary aspergillosis (ABPA) according to Rosenberg-Patterson, adapted from Shah A et al. [44].

Diagnostic Criteria
Major
Asthma
Presence of transient pulmonary infiltrates (fleeting shadows
Immediate cutaneous reactivity to $A$. fumigatus
Elevated total serum IgE
Precipitating antibodies against $A$. fumigatus
Peripheral blood eosinophilia
Elevated serum IgE and IgG to $A$. fumigatus
Central/proximal bronchiectasis with normal tapering of distal bronchi
Minor
Expectoration of golden-brownish sputum plugs
Positive sputum culture for Aspergillus species
Late (Arthus-type) skin reactivity to $A$. fumigatus

In 2013, the ISHAM Working Group defined predisposing conditions such as asthma or CF and then established obligatory criteria consisting of: (1) immediate cutaneous reactivity to A. fumigatus or elevated IgE levels against A. fumigatus and (2) elevated total IgE levels $>1000 \mathrm{IU} / \mathrm{mL}$. They are both needed for diagnosis. In addition, they proposed the following other criteria: (1) the presence of IgG antibodies against $A$. fumigatus or precipitating antibodies, (2) the presence of pulmonary opacities on 
chest X-ray and/or (3) eosinophil count $>500 / \mu \mathrm{L}$ in steroid-naïve patients [16]. Two out of the three criteria are needed for diagnosis. Obligatory criteria and other criteria are presented in Table 4.

Table 3. Diagnostic criteria for allergic bronchopulmonary aspergillosis (ABPA) according to the Cystic

Fibrosis Foundation Consensus Conference, adapted from Stevens DA et al. [14].

\begin{tabular}{c} 
Diagnostic Criteria \\
\hline Cystic fibrosis with acute or subacute clinical deterioration \\
Serum total IgE concentration $>1000 \mathrm{IU} / \mathrm{mL}$ unless the patient is receiving systemic corticosteroids \\
Positive serum-specific IgE $(>0.35 \mathrm{kUA} / \mathrm{L}$ ) or immediate skin test \\
Precipitating antibodies to $A$. fumigatus or serum IgG antibodies to $A$. fumigatus by an in vitro test \\
New or recent infiltrates (or mucus plugging) on chest radiography or CT that do not respond to antibiotics \\
and standard physiotherapy
\end{tabular}

Table 4. Diagnostic criteria for allergic bronchopulmonary aspergillosis (ABPA) according to the ISHAM Working Group, adapted from Agarwal R et al. [16].

\begin{tabular}{c} 
Diagnostic Criteria \\
\hline Obligatory (both needed) \\
Type 1 Aspergillus skin test positive or elevated IgE against $A$. fumigatus \\
Elevated total IgE levels $(>1000 \mathrm{IU} / \mathrm{mL}$ unless all other criteria are met) \\
Other $(\geq 2$ out of 3$):$ \\
Presence of IgG antibodies against $A$. fumigatus or precipitating antibodies \\
Presence of fleeting or fixed pulmonary opacities on chest $\mathrm{X}$-ray \\
Eosinophil count $>500$ cells $/ \mu \mathrm{L}$ in steroid-naïve patients
\end{tabular}

Maleki et al. found no significant effect on the reported prevalence of ABPA in CF patients depending on the applied criteria [45].

Recently, Denning DW et al. suggested a simplified scheme to recognize fungal colonization and sensitisation from ABPA (Table 5, adapted from Denning et al. [46]).

Table 5. Definitions for fungal colonization, fungal sensitisation and allergic bronchopulmonary aspergillosis (ABPA) according to Denning DW et al [46].

\begin{tabular}{|c|c|}
\hline & Proposed Definition \\
\hline Fungal colonization & $\begin{array}{l}\text { 1. One (preferably two or more) respiratory samples positive for Aspergillus by } \\
\text { 2. No new major respiratory symptoms } \\
\text { 3. No evidence of ABPA or other forms of Aspergillosis } \\
\text { 4. No overt immunocompromised } \\
\text { 5. Negative serum Aspergillus IgG }\end{array}$ \\
\hline Fungal sensitization & $\begin{array}{l}\text { Aspergillus skin test positive or elevated IgE against } A \text {. fumigatus without } \\
\text { inflammation or lung damage }\end{array}$ \\
\hline ABPA & $\begin{array}{ll}\text { 1. } & C F \\
\text { 2. } & \text { Aspergillus skin test positive or elevated } \mathrm{IgE} \text { against } \text { A. fumigatus } \\
\text { 3. } & \text { Elevated total } \mathrm{IgE} \text { levels }(>1000 \mathrm{IU} / \mathrm{mL})\end{array}$ \\
\hline
\end{tabular}

The same group proposed a new classification for aspergillosis in CF patients that integrates in the diagnostic criteria sputum galactomannan and real-time Aspergillus PCR with Aspergillus serum-specific IgE and IgG. This classification intends to recognize Aspergillus bronchitis from simple colonization and to differentiate Aspergillus sensitization from ABPA [47]. Latent class analysis of 146 adult patients with CF identified three distinct classes of aspergillosis: ABPA, patients with a positive PCR, elevated total and specific A. fumigatus IgE/IgG and a positive galactomannan; Aspergillus sensitized, patients with or without a positive PCR, elevated A. fumigatus $\operatorname{IgE}$ (not IgG) and a negative sputum galactomannan; Aspergillus bronchitis, patients with a positive PCR, elevated A. fumigatus IgG and a positive sputum 
galactomannan. Interestingly, $17 \%$ of patients moved between classes over a 9-month period of follow-up highlighting the known variability of Aspergillus disease [47].

Together with clinical manifestations and laboratory findings, radiological features can help with the diagnosis. Moreover, chest X-rays and CT scan findings allow further classification of ABPA as follows: (1) ABPA-seropositive (ABPA-S) when patients meet the minimum criteria but without central or peripheral bronchiectasis; (2) ABPA-central bronchiectasis (ABPA-CB) when patients meet the minimum criteria with central bronchiectasis; (3) severe asthma associated with fungal sensitivity (SAFS) when patients with asthma and sensitivity to fungi do not meet the minimum criteria for ABPA $[48,49]$. A recent study by Lu et al. analysed 125 ABPA-CB patients and found that clinical course and prognosis correlated with the radiological phenotype of mucus plugs [50]. Based on their density on $\mathrm{CT}$, mucus plugs have been classified in high-attenuation mucus (HAM) and low-attenuation mucus (LAM). The authors have found that the presence of HAM positively correlates with the severity of the disease. In addition to the lack of unique criteria, ABPA in CF patients can be associated with other respiratory infections caused by both fungi and bacteria, which can themselves determine a decline in impaired lung function, making diagnosis even harder. Many examples of delayed diagnosis due to co-infections can be found in the literature. A recent case report by an Italian group described a case of delayed diagnosis in a 10-year-old child co-infected with Aspergillus and Mycoplasma pneumoniae [51]. Since clinical manifestations might be misleading, there is great need for novel diagnostic tools. Recent studies have highlighted that the use of basophil activation test (BAT) and lymphocyte stimulation test (LST) could both enhance the diagnosis of ABPA [52]. BAT explores immediate hypersensitivity mechanisms by evaluating basophil activation ex vivo, whilst LST investigates delayed hypersensitivity responses. In particular, the level of basophil activation has shown correlation with the impairment of lung function and therefore could possibly be used with a prognostic value [53]. Likewise, the grade of CD4+ and CD8+ activation seems to be fairly accurate in predicting the development of ABPA. These findings are still under investigation as further studies are needed. Another functional test found to be useful in diagnosing and monitoring the course of ABPA before and after treatment is thymus and activation-regulated chemokine (TARC), whose serum levels are higher in ABPA patients and decrease after therapy [53].

Large longitudinal studies are required to define worldwide standardized clinical and immunological criteria to diagnose ABPA and to assess the relationship between these criteria and effective lung damage [13].

\section{Treatment of ABPA in Patients with CF}

The aim of ABPA treatment is to control symptoms, prevent and treat exacerbation, limit lung inflammation and reduce progression to end-stage pulmonary disease. The consequences of delayed treatment are fibrosis, bronchiectasis and loss of lung function [54].

Few studies have been conducted recruiting CF patients; therefore, clinical practice relies on the experience acquired in asthma.

The core of the therapy relies on corticosteroids to control the inflammatory process and azoles to reduce the fungal burden. In Table 6, we report the proposed therapeutic scheme of oral corticosteroids in CF patients with ABPA.

Table 6. Proposed corticosteroid regimen for allergic bronchopulmonary aspergillosis (ABPA), adapted from Ohn at al [55].

\begin{tabular}{cc}
\hline & Regimen \\
\hline Weeks 0-2 & Prednisolone $1 \mathrm{mg} / \mathrm{kg} / \mathrm{day}$ (max $50 \mathrm{mg} /$ die) \\
\hline \multicolumn{2}{c}{ Weeks 2-4 $\quad$ Prednisolone $0.5 \mathrm{mg} / \mathrm{kg} /$ day } \\
\hline Weeks 4-6 & Prednisolone $0.5 \mathrm{mg} / \mathrm{kg} 3$ times per week \\
\hline Weeks 6-8 & Prednisolone $0.5 \mathrm{mg} / \mathrm{kg} 3$ times per week \\
\hline
\end{tabular}


A reduction in serum IgE levels of $25 \%$ after one month of therapy and $60 \%$ after two months of therapy is expected. A serum IgE level decrease of at least $35 \%$ is considered a good therapeutic response [56].

In the last few decades, there has been increasing evidence that antifungal therapy with azoles may play a significant role in the management of ABPA in patients with CF [57], reducing the antigenic stimulus of the fungus and therefore the inflammation cascade [58]. Currently, the most studied molecules are itraconazole and voriconazole. Itraconazole increases corticosteroid plasma levels through a reduction in corticosteroid metabolism, thus allowing for a reduction in oral corticosteroid dosage but also exposing patients under inhaled corticosteroids to unexpected systemic concentrations $[59,60]$. Itraconazole bioavailability varies among individuals and monitoring of serum concentrations is recommended to maintain the right exposure. Voriconazole has better oral bioavailability and is better tolerated (fewer gastrointestinal adverse effects), but phototoxicity has been reported in up to $20 \%$ of children, and this percentage doubles if treated for 6 months or longer [61]. Of note, an association with skin cancer has been described with its long-term use [62,63]. Due to the increased use of triazole drugs, resistant strains of A. fumigatus have been selected [64]. There is emerging evidence that posaconazole can be a valid alternative therapy. The resistance profile is similar to itraconazole, but absorption and tolerance are greater. A retrospective study in 32 patients with CF suggested that posaconazole is more effective than itraconazole and voriconazole at reducing A. fumigatus IgE in ABPA [65]. In a prospective study of 14 children with CF, posaconazole treatment was well tolerated and resulted in a modest but significant improvement in lung function [66]. A case report described a patient with ABPA successfully treated with a new triazole called isavuconazole without serious adverse effects [67]. Randomized controlled studies are needed to evaluate which is the best antifungal treatment for ABPA in patients with CF. Nebulized amphotericin B has been used as a treatment for invasive Aspergillus infection. Therefore, its use has been proposed to treat difficult cases of ABPA. As bronchospasm and cough have been reported as side effects, this medication should be administered under medical surveillance [63].

Since IgE-mediated hypersensitivity is involved in ABPA pathogenesis, omalizumab (i.e., a humanized monoclonal antibody against IgE) use has been proposed for ABPA in CF patients $[68,69]$. Perisson et al. retrospectively analysed 18 patients and observed a stabilization in lung function decline after the initiation of biological therapy with omalizumab along with a notable reduction in the corticosteroid daily dose needed and an improvement in the nutritional status [70]. Similarly, the use of mepolizumab, a humanized monoclonal antibody for IL-5, has been reported in three patients with CF and ABPA and demonstrated good tolerability and a beneficial effect in reducing oral corticosteroids [71]. However, there is a lack of strong evidence for the use of humanized monoclonal antibodies in people with CF and ABPA, and further studies are needed.

CF patients with ABPA were found to have lower levels of serum vitamin D. The therapeutic role of vitamin D in ABPA has been investigated. The addition in vitro of 1,25 OH-vitamin D3 reduced Th2 response and the expression of OX40 ligand on dendritic cells, responsible for the Th2 response mediated by innate airway epithelium cytokines, and potentiated Treg-mediated regulation of Th2 reactivity [72]. A phase I clinical trial demonstrated the efficacy of a daily supplementation with 4.000 UI of vitamin D for 24 weeks in reducing IL-13-mediated Th2 response and Aspergillus-specific IgE levels in CF children aged 12 years with ABPA [73].

IFN- $\gamma$ increases the killing capacities of human neutrophils and monocytes against $A$. fumigatus hyphae and $A$. terreus and the release of pro-inflammatory cytokines. Recombinant IFN- $\gamma$ therapy was therefore used in several clinical trials to treat or at least to prevent fungal infections.

In recent years, promising data came from CFTR modulator drugs that significantly reduced Aspergillus in respiratory cultures [74].

More research is required to determine which is the right treatment and whether anti-fungal therapy influences the course of disease. 


\section{Conclusions}

CF patients with ABPA should undergo regular follow-up. The serum IgE level is the most commonly used parameter to assess the benefit of the treatment. A serum IgE level decrease of at least $35 \%$ is considered a good therapeutic response; doubled IgE levels at any stage indicate an ABPA exacerbation [56]. Given the consequences of a late ABPA diagnosis, it is imperative that the diagnostic criteria guidelines be reviewed and standardized. Moreover, the availability of certain diagnostic criteria is essential to limit the risk of ABPA overdiagnosis. Early treatment of Aspergillus colonization could prevent the progression to ABPA and limit pulmonary damage. However, colonized patients that may not develop ABPA in the future might be exposed to unneeded corticosteroid therapy. Future research studies are needed to prevent Aspergillus colonization, improve the classification and diagnosis of clinical manifestations and find personalized treatments.

In conclusion, the real impact of ABPA in CF patients requires further investigations. Studies on paediatric population are limited and clinical practice is mostly based on experience with adults. Since ABPA is a rare entity in children, we suggest that multicentre studies are implemented in order to have larger cohorts of patients and therefore more conclusive evidence. Moreover, laboratory testing should be standardized to objectively compare results among centres.

Author Contributions: C.L. and G.M. co-wrote the first draft of the manuscript; V.F. and M.C.T. supervised the literature review; G.P. gave a substantial scientific contribution; S.E. supervised the project and made substantial scientific contributions. All authors have read and agreed to the published version of the manuscript.

Funding: This review was supported by the Cystic Fibrosis Center, Parma University Hospital, Parma, Italy.

Conflicts of Interest: The authors declare no conflict of interest.

\section{References}

1. Eickmeier, O.; Rieber, N.; Eckrich, J.; Hector, A.; Graeppler-Mainka, U.; Hartl, D. Immune response, diagnosis and treatment of allergic bronchopulmonary aspergillosis in cystic fibrosis lung disease. Curr. Pharm. Des. 2013, 19, 3669-3678. [CrossRef]

2. Zemanick, E.T.; Hoffman, L.R. Cystic fibrosis: Microbiology and host response. Pediatr. Clin. 2016, 63, 617-636.

3. Amin, R.; Dupuis, A.; Aaron, S.D.; Ratjen, F. The effect of chronic infection with Aspergillus fumigatus on lung function and hospitalization in patients with cystic fibrosis. Chest 2010, 137, 171-176. [CrossRef] [PubMed]

4. Valenza, G.; Tappe, D.; Turnwald, D.; Frosch, M.; König, C.; Hebestreit, H.; Abele-Horn, M. Prevalence and antimicrobial susceptibility of microorganisms isolated from sputa of patients with cystic fibrosis. J. Cyst. Fibros. 2008, 7, 123-127. [CrossRef] [PubMed]

5. Tracy, M.C.; Moss, R.B. The myriad challenges of respiratory fungal infection in cystic fibrosis. Pediatr Pneumol 2018, 53 (Suppl. S3), S75-S85. [CrossRef]

6. Reece, E.; McClean, S.; Greally, P.; Renwick, J. The prevalence of Aspergillus fumigatus in early cystic fibrosis disease is underestimated by culture-based diagnostic methods. J. Microbiol. Methods 2019, 164, 105683. [CrossRef]

7. Jones, A.M.; Horsley, A.; Denning, D.W. What is the importance of classifying Aspergillus disease in cystic fibrosis patients? Expert Rev. Respir. Med. 2014, 8, 389-392. [CrossRef]

8. Saunders, R.V.; Modha, D.E.; Claydon, A.; Gaillard, E.A. Chronic Aspergillus fumigatus colonization of the pediatric cystic fibrosis airway is common and may be associated with a more rapid decline in ling function. Sabouraudia 2016, 54, 537-543. [CrossRef]

9. Breuer, O.; Schultz, A.; Turkovic, L.; De Klerk, N.; Keil, A.D.; Brennan, S.; Harrison, J.; Robertson, C.; Robinson, P.J.; Sly, P.D.; et al. Changing prevalence of lower airway infections in young children with cystic fibrosis. Am. J. Respir. Crit. Care Med. 2019, 200, 590-599. [CrossRef]

10. Sisodia, J.; Bajaj, T. Allergic Bronchopulmonary Aspergillosis (ABPA). In StatPearls; StatPearls Publishing: Treasure Island, FL, USA, 2020. 
11. Keown, K.; Abbott, S.; Kuzeljevic, B.; Rayment, J.H.; Chilvers, M.A.; Yang, C.L. An investigation into biomarkers for the diagnosis of ABPA and Aspergillus disease in cystic fibrosis. Pediatr. Pulmonol. 2019, 54, 1787-1793. [CrossRef] [PubMed]

12. Agarwal, R.; Sehgal, I.S.; Dhooria, S.; Aggarwal, A.N. Developments in the diagnosis and treatment of allergic bronchopulmonary aspergillosis. Expert Rev. Respir. Med. 2016, 10, 1317-1334. [CrossRef] [PubMed]

13. Denning, D.W.; Pleuvry, A.; Cole, D.C. Global burden of allergic bronchopulmonary aspergillosis with asthma and its complications chronic pulmonary aspergillosis in adults. Med. Mycol. 2013, 51, 361-370. [CrossRef] [PubMed]

14. Stevens, D.A.; Moss, R.B.; Kurup, V.P.; Knutsen, A.P.; Greenberger, P.; Judson, M.A.; Denning, D.W.; Crameri, R.; Brody, A.S.; Light, M.; et al. Allergic bronchopulmonary aspergillosis in cystic fibrosis-state of the art: Cystic Fibrosis Foundation Consensus Conference. Clin. Infect. Dis. 2003, 37 (Suppl. 3), S225-S264. [CrossRef] [PubMed]

15. Gothe, F.; Kappler, M.; Griese, M. Increasing Total Serum IgE, Allergic Bronchopulmonary Aspergillosis, and Lung Function in Cystic Fibrosis. J. Allergy Clin. Immunol. Pract. 2017, 5, 1591-1598. [CrossRef]

16. Agarwal, R.; Chakrabarti, A.; Shah, A.; Gupta, D.; Guleria, R.; Moss, R.; Denning, D.W. Allergic bronchopulmonary aspergillosis: Review of literature and proposed of new diagnostic and classification criteria. Clin. Exp. Allergy 2013, 43, 850-873. [CrossRef]

17. Hong, G.; Psoter, K.J.; Jennings, M.T.; Merlo, C.A.; Boyle, M.P.; Hadjiliadis, D.; Kawut, S.M.; Lechtzin, N. Risk factors for persistent Aspergillus respiratory isolation in cystic fibrosis. J. Cyst. Fibros. 2018, 17, 624-630. [CrossRef]

18. Jubin, V.; Ranque, S.; Stremler Le Bel, N.; Sarles, J.; Dubus, J.C. Risk factors for Aspergillus colonization and Allergic Bronchopulmonary Aspergillosis in children with cystic fibrosis. Pediatr. Pulmonol. 2010, 45, 764-771. [CrossRef]

19. Thompson, J.M.; Wesley, A.; Bymes, C.A.; Nixon, G.M. Pulse intravenous metilprednisolone for resistant allergic bronchipulmonary aspergillosis in cystic fibrosis. Pediatr. Pulmonol. 2006, 41, 164-170. [CrossRef]

20. Knutsen, A.P.; Kariuki, B.; Santiago, L.A.; Slvin, R.G.; Wofford, J.D.; Bellone, C.; Shah, M.R. HLADR, IL-4RA, and IL-10: Genetic risk factors in allergic bronchopulmonary aspergillosis. Pediatr. Asthma Allergy Immunol. 2008, 21, 185-190. [CrossRef]

21. Brouard, J.; Knauer, N.; Boelle, P.-Y.; Corvol, H.; Henrion-Caude, A.; Flamant, C.; Brémont, F.; Delaisi, B.; Duhamel, J.; Marguet, C.; et al. Influence of interleukin-10 on Aspergillus fumigatus infection in patients with cystic fibrosis. J. Infect. Dis. 2005, 191, 1988-1991. [CrossRef]

22. Overton, N.L.; Denning, D.W.; Bowyer, P.; Simpson, A. Genetic susceptibility to allergic bronchopulmonary aspergillosis in asthma: A genetic association study. Allergy Asthma Clin. Immunol. 2016, 12, 47. [CrossRef]

23. Kolwijck, E.; van de Veerdonk, F.L. The potential impact of the pulmonary microbiome on immunopathogenesis of Aspergillus-related lung disease. Eur. J. Immunol. 2014, 44, 3156-3165. [CrossRef] [PubMed]

24. Noverr, M.C.; Noggle, R.M.; Toews, G.B.; Huffnagle, G.B. Role of antibiotics and fungal microbiota in driving pulmonary allergic responses. Infect. Immun. 2004, 72, 4996-5003. [CrossRef]

25. Moss, R.B. Pathophysiology and immunology of allergic bronchopulmonary aspergillosis. Med. Mycol. 2005, 43 (Suppl. 1), S203-S206. [CrossRef] [PubMed]

26. Agarwal, R. Allergic bronchopulmonary aspergillosis. Chest 2009, 135, 805-826. [CrossRef] [PubMed]

27. Wiesner, D.L.; Klein, B.S. Lung epithelium: Barrier immunity to inhaled fungi and driver of fungal-associated allergic asthma. Curr. Opin. Microbiol. 2017, 40, 8-13. [CrossRef]

28. Mueller, C.; Braag, S.A.; Keeler, A.; Hodges, C.; Drumm, M.; Flotte, T.R. Lack of cystic fibrosis transmembrane conductance regulator in CD3+ lymphocytes leads to aberrant cytokine secretion and hyperinflammatory adaptive immune responses. Am. J. Respir. Cell Mol. Boil. 2011, 44, 922-929. [CrossRef]

29. Millien, V.O.; Lu, W.; Shaw, J.; Yuan, X.; Mak, G.; Roberts, L.; Song, L.-Z.; Knight, J.M.; Creighton, C.J.; Luong, A.; et al. Cleavage of fibrinogen by proteinases elicits allergic responses through Toll-like receptor 4. Science 2013, 341, 792-796. [CrossRef]

30. Cunha, C.; Romani, L.; Carvalho, A. Cracking the Toll-like receptor code in fungal infections. Expert Rev. Anti-Infect. Ther. 2010, 8, 1121-1137. [CrossRef]

31. Bellocchio, S.; Moretti, S.; Perruccio, K.; Fallarino, F.; Bozza, S.; Montagnoli, C.; Mosci, P.; Lipford, G.B.; Pitzurra, L.; Romani, L. TLRs govern neutrophil activity in aspergillosis. J. Immunol. 2004, 173, 7406-7415. [CrossRef] 
32. Knutsen, A.P.; Hutchinson, P.S.; Albers, G.M.; Consolino, J.; Smick, J.; Kurup, V.P. Increased sensitivity to IL-4 in cystic fibrosis patients with allergic bronchopulmonary aspergillosis. Allergy 2004, 59, 81-87. [CrossRef] [PubMed]

33. Dietschmann, A.; Schruefer, S.; Krappmann, S.; Voehringer, D. Th2 cells promote eosinophil independent pathology in a murine model of allergic bronchopulmonary aspergillosis. [published online ahead of print, 28 February 2020]. Eur. J. Immunol. 2020. [CrossRef] [PubMed]

34. Gago, S.; Denning, D.W.; Bowyer, P. Pathophysiological aspects of Aspergillus colonization in disease. Med. Mycol. 2019, 57 (Suppl. 2), S219-S227. [CrossRef] [PubMed]

35. Kosmidis, C.; Denning, D.W. The clinical spectrum of pulmonary aspergillosis. Thorax 2015, 70, $270-277$. [CrossRef]

36. Brandt, C.; Roehmel, J.; Rickerts, V.; Melichar, V.; Niemann, N.; Schwarz, C. Aspergillus Bronchitis in Patients with Cystic Fibrosis. Mycopathologia 2018, 183, 61-69. [CrossRef]

37. Patel, A.R.; Singh, S.; Khawaja, I. Diagnosing allergic bronchopulmonary aspergillosis: A review. Cureus 2019, 11, e4550. [CrossRef]

38. Kaditis, A.G.; Miligkos, M.; Bossi, A.; Colombo, C.; Hatziagorou, E.; Kashirskaya, N.; De Monestrol, I.; Thomas, M.; Mei-Zahav, M.; Chrousos, G.; et al. Effect of allergic bronchopulmonary aspergillosis on FEV1 in children and adolescents with cystic fibrosis: A European Cystic Fibrosis Society Patient Registry analysis. Arch. Dis. Child. 2017, 102, 742-747. [CrossRef]

39. De Baets, F.; De Keyzer, L.; Van Daele, S.; Schelstraete, P.; Van Biervliet, S.; Van Braeckel, E.; Thomas, M.; Wanyama, S.S. Risk factors and impact of allergic bronchopulmonary aspergillosis in Pseudomonas aeruginosa-negative CF patients. Pediatr. Allergy Immunol. 2018, 29, 726-731. [CrossRef]

40. Harun, S.N.; Wainwright, C.E.; Grimwood, K.; Henning, S. Aspergillus and progression of lung disease in children with cystic fibrosis. Thorax 2018, 74, 125-131. [CrossRef]

41. Breuer, O.; Schultz, A.; Garratt, L.W.; Turkovic, L.; Rosenow, T.; Murray, C.P.; Karpievitch, Y.V.; Akesson, L.; Dalton, S.; Sly, P.D.; et al. Aspergillus Infections and Progression of Structural Lung Disease in Children with Cystic Fibrosis. Am. J. Respir. Crit. Care Med. 2020, 201, 688-696. [CrossRef]

42. Noni, M.; Katelari, A.; Dimopoulos, G.; Doudounakis, S.E.; Tzoumaka-Bakoula, C.; Spoulou, V. Aspergillus fumigatus chronic colonization and lung function decline in cystic fibrosis may have a two-way relationship. Eur. J. Clin. Microbiol. Infect. Dis. 2015, 34, 2235-2241. [CrossRef] [PubMed]

43. Beswick, E.; Amich, J.; Gago, S. Factoring in the Complexity of the Cystic Fibrosis Lung to Understand Aspergillus fumigatus and Pseudomonas aeruginosa Interactions. Pathogens 2020, 9, 639. [CrossRef] [PubMed]

44. Shah, A.; Panjabi, C. Allergic bronchopulmonary aspergillosis: A perplexing clinical entity. Allergy Asthma Immunol. Res. 2016, 8, 282-297. [CrossRef] [PubMed]

45. Maleki, M.; Mortezaee, V.; Hassanzad, H.; Mahdaviani, S.; Poorabdollah, M.; Mehrian, P.; Behnampour, N.; Mirenayat, M.; Abastabar, M.; Tavakoli, M.; et al. Prevalence of allergic bronchopulmonary aspergillosis in cystic fibrosis patients using two different diagnostic criteria. Eur. Ann. Allergy Clin. Immunol. 2020, 52, 104-111. [CrossRef]

46. Denning, D.W.; Pashley, C.; Hartl, D.; Wardlaw, A.; Godet, C.; Del Giacco, S.; Delhaes, L.; Sergejeva, S. Fungal allergy in asthma-state of the art and research needs. Clin. Transl. Allergy 2014, 4, 14. [CrossRef]

47. Baxter, C.G.; Dunn, G.; Jones, A.M.; Webb, K.; Gore, R.; Richardson, M.D.; Denning, D.W. Novel immunologic classification of aspergillosis in adult cystic fibrosis. J. Allergy Clin. Immunol. 2013, 132, 560-566.e10. [CrossRef]

48. Knutsen, A.P.; Bush, R.K.; Demain, J.G.; Denning, D.W.; Dixit, A.; Fairs, A.; Greenberger, P.A.; Kariuki, B.; Kita, H.; Kurup, V.P.; et al. Fungi and allergic lower respiratory tract diseases. J. Allergy Clin. Immunol. 2012, 129, 280-291. [CrossRef]

49. Agarwal, R.; Garg, M.; Aggarwal, A.N.; Saikia, B.; Gupta, D.; Chakrabarti, A. Serologic allergic bronchopulmonary aspergillosis (ABPA-S): Long term outcomes. Respir. Med. 2012, 106, 942-947. [CrossRef]

50. Lu, H.W.; Mao, B.; Wei, P.; Jiang, S.; Wang, H.; Li, C.W.; Ji, X.B.; Gu, S.Y.; Yang, J.W.; Liang, S.; et al. The clinical characteristics and prognosis of ABPA are closely related to the mucus plugs in central bronchiectasis. Clin. Respir. J. 2020, 14, 140-147. [CrossRef]

51. Peccini, L.; Pennoni, S.; Mencarini, V.; Saponara, M.; Palladino, N.; Principi, N.; Pennoni, G.; Esposito, S. A peculiar case of pneumonia due to Mycoplasma pneumoniae in a child with cystic fibrosis and sensibilization to Aspergillus fumigatus. Pathogens 2019, 9, 15. [CrossRef] 
52. Michel, M.; Gomez, C.; Sereme, Y.; Gouitaa, M.; Chartier, C.; Blanchard, P.; Pinchemel, S.; Cassagne, C.; Ranque, S.; Mege, J.L.; et al. Evaluation of Cellular Responses for the Diagnosis of Allergic Bronchopulmonary Mycosis: A Preliminary Study in Cystic Fibrosis Patients. Front. Immunol. 2020, 10, 3149. [CrossRef] [PubMed]

53. Hemmings, O.; Kwok, M.; McKendry, R.; Santos, A.F. Correction to: Basophil Activation Test: Old and New Applications in Allergy. Curr. Allergy Asthma Rep. 2019, 19, 58. [CrossRef]

54. Patel, A.R.; Singh, S.; Khawaja, I. Treating allergic bronchopulmonary aspergillosis: A review. Cureus 2019, 11, e4538. [CrossRef] [PubMed]

55. Ohn, M.; Robinson, P.; Selvadurai, H.; Fitzgerald, D.A. Question 11: How should allergic bronchopulmonary aspergillosis (ABPA) be managed in cystic fibrosis? Paediatr. Respir. Rev. 2017, 24, 35-38. [CrossRef] [PubMed]

56. Natarajan, S.; Subramanian, P. Allergic bronchopulmonary aspergillosis: A clinical review of 24 patients: Are we right in frequent serologic monitoring? Ann. Thorac. Med. 2014, 9, 216. [CrossRef]

57. Agarwal, R.; Dhooria, S.; Sehgal, I.S.; Aggarwal, A.N.; Garg, M.; Saikia, B.; Behera, D.; Chakrabarti, A. A randomized trial of Itraconazole vs Prednisolone in acute-stage allergic bronchopulmonary aspergillosis complicating asthma. Chest 2018, 153, 656-664. [CrossRef] [PubMed]

58. Agarwal, R. What is the current place of azoles in allergic bronchopulmonary aspergillosis and severe asthma with fungal sensitization. Expert Rev. Respir. Med. 2012, 6, 363-371. [CrossRef]

59. Elphick, H.E.; Southern, K.W. Antifungal therapies for allergic bronchopulmonaryaspergillosis in people with cystic fibrosis. Cochrane Database Syst. Rev. 2016, 11. [CrossRef]

60. Denning, D.W.; O’Driscoll, B.R.; Powell, G.; Chew, F.; Atherton, G.T.; Vyas, A.; Miles, J.; Morris, J.; Niven, R.M. Randomized controlled trial of oral antifungal treatment for severe asthma with fungal sensitization: The Fungal Asthma Sensitization Trial (FAST) study. Am. J. Respir. Crit. Care Med. 2009, 179, 11-18. [CrossRef]

61. Sheu, J.; Hawryluk, E.B.; Guo, D.; London, W.B.; Huang, J.T. Voriconazole phototoxicity in children: A retrospective review. J. Am. Acad. Dermatol. 2015, 72, 314-320. [CrossRef]

62. El-Baba, F.; Gao, Y.; Soubani, A.O. Pulmonary Aspergillosis: What the Generalist Needs to Know. Am. J. Med. 2020, 133, 668-674. [CrossRef] [PubMed]

63. Clancy, C.J.; Nguyen, M.H. Long-term voriconazole and skin cancer: Is there cause for concern? Curr. Infect. Dis. Rep. 2011, 13, 536-543. [CrossRef] [PubMed]

64. Rivero-Menendez, O.; Alastruey-Izquierdo, A.; Mellado, E.; Cuenca-Estrella, M. Triazole resistance in Aspergillus spp.: A worldwide problem? J. Fungi 2016, 2, 21. [CrossRef] [PubMed]

65. Periselneris, J.; Nwankwo, L.; Schelenz, S.; Shah, A.; Armstrong-James, D. Posaconazole for the treatment of allergic bronchopulmonary aspergillosis in patients with cystic fibrosis. J. Antimicrob. Chemother. 2019, 74, 1701-1703. [CrossRef] [PubMed]

66. Patel, D.; Popple, S.; Claydon, A.; Modha, D.E.; Gaillard, E.A. Posaconazole therapy in children with cystic fibrosis and Aspergillus-related lung disease. Med. Mycol. 2019, 58, 11-21. [CrossRef]

67. Jacobs, S.E.; Saez-Lacy, D.; Wynkoop, W.; Walsh, T.J. Successful Treatment of Allergic Bronchopulmonary Aspergillosis with Isavuconazole: Case Report and Review of the Literature. In Open Forum Infectious Diseases; Oxford University Press: Oxford, UK, 2017; Volume 4.

68. Voskamp, A.L.; Gillman, A.; Symons, K.; Sandrini, A.; Rolland, J.M.; O’Heir, R.E.; Douglass, J.A. Clinical efficacy and immunologic effects of Omalizumab in allergic bronchopulmonary aspergillosis. J. Allergy Clin. Immunol. Pr. 2015, 3, 192-199. [CrossRef]

69. Koutsokera, A.; Corriveau, S.; Sykes, J.; Coriati, A.; Cortes, D.; Vadas, P.; Chaparro, C.; Mclntyre, K.; Tullis, E.; Stephenson, A.L. Omalizumab for asthma and allergic bronchopulmonary aspergillosis in adults with cystic fibrosis. J. Cyst. Fibros. 2020, 19, 119-124. [CrossRef]

70. Perisson, C.; Destruys, L.; Grenet, D.; Bassinet, L.; Derelle, J.; Sermet-Gaudelus, I.; Thumerelle, C.; Prevotat, A.; Rosner, V.; Clement, A.; et al. Omalizumab treatment for allergic bronchopulmonary aspergillosis in young patients with cystic fibrosis. Respir. Med. 2017, 133, 12-15. [CrossRef]

71. Zhang, L.; Borish, L.; Smith, A.; Somerville, L.; Albon, D. Use of mepolizumab in adult patients with cystic fibrosis and an eosinophilic phenotype: Case series. Allergy Asthma Clin. Immunol. 2020, 16, 3. [CrossRef]

72. Kreindler, J.L.; Steele, C.; Nguyen, N.; Chan, Y.R.; Pilewski, J.M.; Alcorn, J.F.; Vyas, Y.M.; Aujla, S.J.; Finelli, P.; Blanchard, M.; et al. Vitamin D3 attenuates Th2 responses to Aspergillus fumigatus mounted by CD4+ T cells from cystic fibrosis patients with allergic bronchopulmonary aspergillosis. J. Clin. Investig. 2010, 120, 3242-3254. [CrossRef] 
73. Nguyen, N.L.H.; Pilewski, J.M.; Celedón, J.C.; Mandalapu, S.; Blanchard, M.L.; De Ricco, A.; Hartigan, E.; Alcorn, J.F.; Kolls, J.K. Vitamin D supplementation decreases Aspergillus fumigatus specific Th2 responses in CF patients with aspergillus sensitization: A phase one open-label study. Asthma Res. Pr. 2015, 1, 3. [CrossRef] [PubMed]

74. Frost, F.J.; Nazareth, D.S.; Charman, S.C.; Winstanley, C.; Walshaw, M.J. Ivacaftor Is Associated with Reduced Lung Infection by Key Cystic Fibrosis Pathogens. A Cohort Study Using National Registry Data. Ann. Am. Thorac. Soc. 2019, 16, 1375-1382. [CrossRef] [PubMed]

(C) 2020 by the authors. Licensee MDPI, Basel, Switzerland. This article is an open access article distributed under the terms and conditions of the Creative Commons Attribution (CC BY) license (http://creativecommons.org/licenses/by/4.0/). 